\section{Generationing, stealthing, and gift giving: the intentional transmission of HIV by HIV-positive men to their HIV-negative sex partners}

\author{
Hugh Klein \\ Kensington Research Institute, Silver \\ Spring, MD, USA
}

\section{Abstract}

Gift giving is the process by which an HIVpositive person purposely infects an HIV-negative person with HIV, usually with that person's knowledge and consent. Little has been written about this HIV transmission practice. In this paper, two specific types of gift giving - generationing and stealthing - are explained and introduced to the scientific literature. Generationing is a type of gift giving in which one gift giver successfully infects a previouslyuninfected man with HIV, and then the two men collaborate in an effort to seroconvert another man, and so forth. Stealthing is another type of gift giving in which an HIV-positive man actively tries to infect an HIV-negative man with HIV, without the latter's knowledge or consent. The present study reports on the prevalence of gift giving (4.6\%) in a population of men who use the Internet specifically to identify partners for unprotected sex. The research is based on a national random sample of 332 men who have sex with men, identified from 16 websites. Data were collected via telephone interviews conducted between January 2008 and May 2009. The paper concludes with a discussion of the implications of these findings for HIV prevention and intervention efforts. Most notably, to the extent that generationing, stealthing, and gift giving occur among MSM, they represent a very high risk of HIV transmission. More work needs to be done to understand these behaviors, the factors that underlie them, and to determine how prevalent they are in the bare-backing population of MSM.

\section{Introduction}

Barebacking is a practice in which people purposely engage in unprotected anal sex. Although the prevalence of barebacking is unknown among men who have sex with other men (MSM), this behavior is linked closely to the transmission of HIV in this population. Two subgroups of the larger population of barebacking MSM are referred to as bug chasers and gift givers. Bug chasers are HIVnegative men who actively seek unprotected sex with HIV-positive partners, so that they themselves can become HIV-infected. Their active pursuit (chasing) of the HIV virus (bug) gives rise to their moniker. Bug chasers' counterparts are known as gift givers: HIV-positive men who seek unprotected sex with HIV-negative partners, so that they can seroconvert their partners to being HIV-positive. The term gift giver derives from the notion that HIV-positive men have something special that can be cherished (the gift) that they can transmit to other men (giving). The existence of these subgroups within the MSM barebacker culture has led some authors to conclude that bug chasers (and presumably gift givers as well) constitute an actual subculture within the broader grouping of barebacking men. ${ }^{1}$

Little has been written in the scientific literature about bug chasers, and even less has been documented with regard to gift givers. The latter is the focus of the present article. Both subgroups appear to be relatively small, comprising a total (bug chasers + gift givers) of anywhere from $1.0 \%$ to $9.7 \%$ of the overall population of barebacking MSM.2-4 Bug chasers appear to outnumber gift givers by approximately $3: 2$; but limited research makes this ratio difficult to confirm. If a distinction is made between committed or ardent gift givers - that is, those who are seeking to have sex only with confirmed HIV-negative sex partners - and passive or opportunistic gift givers - that is, those who wish to have sex with HIV-negative partners and/or with those whose HIV serostatus is unknown and unconfirmable then the prevalence of gift givers in the barebacking population rises to $23-26 \%$. 2,4 Recent evidence suggests that both bug chasing and gift giving are increasing in prevalence. 2,4

The increasing use of the Internet to find sex partners for barebacking is usually attributed to this rise. ${ }^{4}$ Some scholars have claimed that medical advances that make HIV infection a chronic manageable disease rather than a condition that is likely to lead to short-term death have contributed to increases in bug chasing and gift giving behaviors, because some do not perceive HIV infection in themselves or their sex partners to be particularly problematic anymore. ${ }^{5}$ Gift giving, as with bug chasing, may be attributable, at least in part, to a desire for excitement, thrills, and rule breaking, which many people find sexually arousing. 5

Very little has been written in the scientific literature about the practices involved in gift giving or how gift givers feel about engaging in these practices. Recently, Moskowitz and Roloff spoke of gaps in our scientific knowledge regarding gift givers, ${ }^{6}$ specifically in terms of whether or not these individuals
Correspondence: Hugh Klein, Kensington Research Institute, 401 Schuyler Road, Silver Spring, MD 20910, USA.

Tel.: +1.301.588.8875 - Fax: +1.443.885.8262

E-mail: hughk@aol.com; hughkhughk@yahoo.com

Key words: men who have sex with men, HIV risk practices, Internet, gift giving, HIV transmission, generationing.

Acknowledgments: this research was supported by a grant from the National Institute on Drug Abuse (5R24DA019805). The author wishes to acknowledge, with gratitude, the contributions made by Thomas Lambing to the data collection, data entry, and data cleaning efforts done for this study.

Conflict of interests: the authors declare no potential conflict of interests.

Received for publication: 17 April 2014.

Revision received: 31 July 2014.

Accepted for publication: 4 August 2014.

This work is licensed under a Creative Commons Attribution NonCommercial 3.0 License (CC BYNC 3.0).

(C) Copyright H. Klein, 2014

Licensee PAGEPress, Italy

Health Psychology Research 2014; 2:1582

doi:10.4081/hpr.2014.1582

engage in stealth infections (what those authors called sneaking) of HIV-negative men. Those authors acknowledged that scientists have documented little about the extent to which gift givers are (or are not) the mirror image of bug chasers - the proverbial yin to the bug chasers' yang. In the present report, the prevalence of gift giving in a sample of Internet-using barebacking men is examined. In addition, two phenomena that appear to be unique to the gift giving experience - namely, generationing and stealthing - are discussed. The purpose of this article is to shed some light on these particular gift giving-related practices, and to discuss their implications for HIV prevention and intervention.

\section{Materials and Methods}

This paper draws from data that were collected between January 2008 and May 2009 for The Bareback Project. The study sample consisted of men who use the Internet specifically to find other men with whom they can engage in unprotected sex. Some of the 16 websites from which the sample of 332 men were recruited catered exclusively to unprotected sex (e.g., Bareback.com, RawLoads.com). 
These sites accounted for $50.9 \%$ of the men subsequently recruited into the study. The other websites used did not cater to unprotected sex exclusively but did make it possible for site users to identify which men were looking for unprotected sex (e.g., Men4SexNow.com, Squirt.org). These sites supplied $49.1 \%$ of the men for the sample.

\section{Recruitment}

A nationwide sample of men was derived, with random selection of participants being based on a combination of the first letter of the person's online username, his race/ethnicity (as listed in his profile), and the day of recruitment. Each day, members of the research staff working on recruitment had three letters or numerals assigned to them for their use that day. These letters and numerals were assigned randomly. The first letter/numeral was restricted for use for recruiting Caucasian men only; the last two letters/numerals were to be used exclusively for recruiting men of color. (This oversampling technique for racial minority group men was adopted so as to compensate for the fact that men of color, especially African-American men, are more difficult to recruit into research studies than their Caucasian counterparts are.) In order for a particular person to be approached and asked to participate in the study, these letters/numerals had to correspond to the first letter/numeral of that individual's profile and that person's race/ethnicity, as stated in his profile, had to be a match for the Caucasian-versus-racialminority-group-member designation on the daily randomization listing. On recruitment sites where it was possible to know who was online at the time the recruiter was working, selection of potential study participants came from the pool of men who happened to be logged onto the site at the time when the recruiter was working. All men who were online at that time and whose profile name began with the appropriate letter/numeral were eligible to be approached. On recruitment sites where it was not possible to know who was online at the time the recruiter was working, ZIP codes were used to narrow down the pool of men who could be approached. To do this, in addition to the daily three letters/numerals that were assigned to each recruiter throughout the study, each day, ten five-digit numbers were also assigned to each recruiter (five to be used for Caucasian men, five to be used for men of color). These fivedigit numbers were random number combinations and they were used in this study as proxies for ZIP codes. Recruiters entered the first five-digit number into the website's ZIP code search field (which site users typically utilized to identify potential sex partners who resided within a specified radius from their residence), selected a five-mile radius, and then viewed the profile names of all men meeting those criteria who had logged onto that site within the previous 24 hours. Recruiters then reviewed the profiles of potentially-eligible men the letter/numeral match described above for men who were online at the time that recruiters were working.

Recruitment efforts were undertaken seven days a week, during all hours of the day and nighttime, variable from week to week throughout the duration of the project. This was done to maximize the representativeness of the final research sample, in recognition of the fact that different people use the Internet at different times.

\section{Participation}

Initially, men were approached for participation either via instant message or email (much more commonly via email), depending upon the website used. Potential participants were provided with a brief overview of the study and informed consent-related information, and they were given the opportunity to ask questions about the study before deciding whether or not to participate. Interested men were scheduled for an interview soon after they expressed an interest in taking part in the study, typically within a few days. To maximize convenience for participants, interviews were conducted during all hours of the day and night, seven days a week, based on interviewer availability and participants' preferences.

Participants in the study completed a onetime, confidential telephone interview addressing a wide array of topics, including degree of outness, perceived discrimination based on sexual orientation, general health practices, HIV testing history and serostatus, sexual practices (protected and unprotected) with partners met online and offline, riskrelated preferences, risk-related hypothetical situations, substance use, drug-related problems, Internet usage, psychological functioning, childhood maltreatment experiences, HIV/AIDS knowledge, and basic demographic information. The questionnaire that was used was developed specifically for The Bareback Project. Many parts of the survey instrument were derived from standardized scales previously used and validated by other researchers. Interviews lasted an average of 69 minutes (median: 63, $\mathrm{SD}=20.1$, range: 30-210). Participants who completed the interview were offered $\$ 35$. Approval of the research protocol was given by the institutional review boards at Morgan State University, where the principal investigator and one of the research assistants were affiliated, and George Mason University, where the other research assistant was located.

\section{Qualitative data}

Although the Bareback Project was primarily a quantitative study, qualitative data accompa- ny the quantitative interviews for nearly threequarters of the study participants $(n=246)$. The qualitative data took the form of postinterview narrative summaries (what qualitative researchers often refer to as memos, or memoing), 7,8 in which the interviewers recorded personal observations and thoughts, direct quotes from the participants themselves, and contextual information that the interviewers believed would help to place the quantitative interview data into proper perspective. Each of the qualitative narrative summaries was anywhere from one-half of one page to three pages in length, depending upon how talkative the study participant was during and/or after the interview, and upon how much useful information the interviewer felt should be recorded at the interview's conclusion. The idea underlying the memoing process was to capture information that otherwise would have been lost if the study had relied solely upon the quantitative information contained in the survey instrument -information that, hopefully, could be used to illuminate and inform major study findings. It was from these qualitative data that the constructs of generationing and stealthing discussed below were identified.

\section{Measures used}

HIV serostatus is based on men's selfreports. The desired HIV serostatus of their sex partners was ascertained by asking men: When you are looking to meet someone online for a possible sexual hook-up, which of the following statements is most true for you: 1) He must be HIV-negative, 2) You would prefer that he is HIV-negative, 3) It does not matter to you whether he is HIV-positive or HIV-negative, 4) You would prefer that he is HIV-positive, or 5) He must be HIV-positive. Thus, one way of defining gift givers is to focus on the HIV-positive men, and identify which ones responded with \#1 or \#2. This is a way of defining active gift giving (what other researchers have termed ardent or committed gift giving) Passive gift giving (what other researchers have termed opportunistic gift giving) can be defined by including HIV-positive men who responded \#1, \#2, or \#3 to this question.

Elsewhere in the questionnaire, men were posed a series of questions about hypothetical sexual situations in which sex with an HIVserodiscordant partner might occur. The scenarios were identical other than in the types of sex that were posed (insertive anal sex, receptive anal sex, insertive oral sex, receptive oral sex). In each scenario, men were asked what they thought they would be most likely to do. HIV-positive men were asked to indicate whether they would tell the would-be sex partner (1) that they were HIV-positive, (2) that they were HIV-negative, (3) nothing whatsoever about their HIV serostatus, or (4) that they were HIV-positive only if the person specifical- 
ly asked about that. These items lead to another way of defining gift giving -namely, by men who responded \#2 or \#3 (active gift giving) or \#2, \#3, or \#4 (passive gift giving).

\section{Results}

\section{Sample characteristics}

In total, 332 men participated in the study. They ranged in age from 18 to 72 (mean: 43.7, $\mathrm{SD}=11.2$, median: 43.2). Racially, the sample is a fairly close approximation of the American population, ${ }^{9}$ with $74.1 \%$ being Caucasian, $9.0 \%$ each being African American and Latino, 5.1\% self-identifying as biracial or multiracial, $2.4 \%$ being Asian, and $0.3 \%$ being Native American. The large majority of the men (89.5\%) considered themselves to be gay and almost all of the rest $(10.2 \%)$ said they were bisexual. On balance, men participating in The Bareback Project were fairly well-educated. About 1 man in 7 (14.5\%) had completed no more than high school; $34.3 \%$ had some college experience without earning a college degree; $28.9 \%$ had a bachelor's degree; and $22.3 \%$ were educated beyond the bachelor's level. Consistent with the demography of the U.S. population, $1028.0 \%$ of the men lived in rural or low-density population areas (fewer than 500 persons per square mile), $23.5 \%$ lived in urban or higher-density population areas (more than 5000 persons per square mile). Slightly more than one-half of the men (59.0\%) reported being HIV-positive; most of the rest (38.6\%) were HIV-negative.

\section{Prevalence of gift giving}

Using the first definition of gift giving (selfreported HIV serostatus combined with expressed preference for HIV serostatus of sex partners), $2.1 \%$ of the HIV-positive men could be construed as active/committed gift givers and $30.3 \%$ could be construed as passive/opportunistic gift givers. Using the second definition of gift giving (self-reported HIV serostatus combined with HIV serostatus disclosure practices to sex partners in hypothetical sexual situations), $2.6 \%$ of the HIV-positive men could be construed as active/committed gift givers and $21.1 \%$ could be construed as passive/opportunistic gift givers. When the variables are recomputed such that either of the criteria for defining active/committed gift giving and passive/opportunistic gift giving is met, $4.6 \%$ of the HIV-positive men participating in this study can be construed as active/committed gift givers and $40.4 \%$ can be considered passive/opportunistic gift givers.

\section{Generationing}

Generationing is a term that arose initially in conjunction with a lengthy post-interview discussion with $\mathrm{R} 986$. It is a practice by which one person who is HIV-positive intentionally infects someone who is HIV-negative, most commonly via unprotected anal sex involving internal ejaculation. In most situations, the unprotected anal sex is repeated a few times during a particular sex session, so that the chances of infecting the HIV-negative partner are increased. Commenting on this experience, R986 remarked: I find it incredibly sensual to think of having my DNA inside of another man, who then can pass it on to other men for me. . . The more they want my poz charged cum, the more I want to give it to them - the more I need to give it to them.

When the receptive partner seroconverts (proof of which, typically in the form of printed HIV lab test results, is usually required before the gift giver considers the process of generationing to have been successful), he becomes the original HIV-positive man's HIV son -that is, his first HIV-infected generation. Having successfully seroconverted one person, the first man then coordinates with that newlyinfected man to find another man whom they are certain is HIV-negative, and together they arrange a sex session in which both men try to infect person \#3 via unprotected sex (especially, but not necessarily exclusively, unprotected anal sex). According to R986, he and his son take turns engaging in insertive unprotected anal sex with man \#3, with each man taking turns ejaculating inside of \#3's anus a few times. When they have successfully infected this third person, he becomes the HIV grandson of the original man - that is, his HIVinfected second generation. Subsequently, the three men (original HIV-infected man, son, and grandson) work together to find a new person who is HIV-negative, whom all three of them can, as a group, try to infect. In so doing, they create generations of HIV progeny. Living in an urban area that has many MSM makes the process of generationing much easier to undertake, as there are more men who are willing to (if not downright interested in) participate in group sex sessions involving the intentional transmission of HIV to one or more of the participants. At the time of his study interview, R986 - who was an articulate, welleducated man whose involvement in generationing was a well-thought-out, carefully-engineered practice executed over the course of several years of his adult life - had managed to establish a link of eight generations. Indeed, he expressed disappointment at having to relocate to a new city in the near future, commenting: It [relocating] makes generationing very difficult, because the guys are spread so far apart. It's hard to get them all together to keep the generationing going.

He spoke of his ongoing discussions with the men comprising his eight recently-infected generations, and how, as a group, they were planning to try to keep their generationing an ongoing practice after his relocation. One plan was for all of the men to meet in his current (soon-to-be ex) city of residence two or three times a year and convene a bareback sex party in which there would be additional opportunities to proceed with creating new HIV generations. Another plan the men were contemplating entailed having all of the men fly to some locale together once or twice a year, and treat that as a generationing-focused vacation.

\section{Stealthing}

Stealthing is a practice in which an HIV-positive man intentionally tries to infect an HIVnegative man without the latter's knowledge or consent. This practice goes by other names a well, the most common of which appear to be sneaking and stealth fucking. ${ }^{6}$ Depending upon the gift giver in question, stealthing takes numerous forms, some of which are more overtly aggressively gift giving in nature and some of which are more passively gift giving in their implementation.

One especially active manifestation of stealthing takes the form of a process named booty bumping, in which an HIV-positive man packs the foreskin of his penis with a drug, usually methamphetamine (occasionally powder cocaine), and then engages in insertive unprotected anal sex with a man who is HIVnegative. Booty bumping gets its name from the physical locale of the sex on the body, referring to the anus (booty), and the way of enhancing the drug-related high (bumping). It should be noted that not all booty bumping entails the transmission - intentional or unintentional - of HIV, as the behavior is also practiced by men who simply like to get high as part of their sex acts. (An excellent, ongoing discussion of this practice among MSM may be found online, in the Sex with Drugs section of the http://tribes.tribe.net website.) As a type of stealthing, however, booty bumping ordinarily entails a discussion whereby the two partners agree to engage in anal sex, without the receptive partner being aware of the exact manner in which it is going to be done to him. For example, the insertive partner may tell the receptive partner that he will be wearing a condom, and then get the man into a position for anal sex in which the receptive partner cannot see whether or not the insertive partner is, indeed, wearing a condom. Packing his unprotected penis' foreskin with his drug of choice, he then inserts his penis, condomless, into the receptive partner's anus and the drug gets into the receptive partner's circulatory system through the anal capillaries. As the drug begins to take effect, the receptive partner not only becomes high, but also loses his sexual inhibitions regarding how the way the remainder of the sexual act unfolds. The qualitative notes for R986, who was an avid booty bumper, described the process in the following manner: 
[T]he partner becomes high on methamphetamine directly through the anal sex practice, and comes to crave the sex all the more. R986 said that 8 out of $10 \mathrm{HIV}$-negative men with whom he has sex say that they are willing to try booty bumping with him, provided that he agrees not to ejaculate inside of them. Although he never plans to honor this promise, he makes the promise so that he can be allowed to perform anal sex on them, with the full knowledge/expectation that the majority of them will not insist on him withdrawing prior to ejaculation once the methamphetamine gets into their system. He said that of the 8 of 10 men who agree to try this with him, at least 5 beg him not to withdraw when it actually comes time for him to ejaculate. The other 3 , he made it a point of telling me, either say nothing in response to his Where do you want me to cum? question (in which case he automatically ejaculates inside of them, by default) or ask him to pull out, in which case he forces them down and makes them receive his semen anyway.

He commented that, of the men in the latter group, almost always, they are too high to put up too much of a fight or they are so high that they do not care that he is having his way with them, provided that he can bring his anal sex act to completion.

Another way in which stealthing takes place is more passive in nature, but is a gift giving behavior just the same. It might be termed convenient omission of information or answer dodging and it entails purposely failing to disclose one's HIV-positive serostatus when asked a direct question about it by a sex partner. Rather than outright lying and telling the sex partner that one knows that one is HIV-negative when, in fact, one is HIV-positive, this particular practice involves a variety of ways of not answering the HIV serostatus question. Some men change the subject in an inconspicuous way, so that the questioner thinks that he got an answer (or due to the diverted discussion that takes place, subsequently forgets that he did not get an answer to his question) when, in fact, he did not. Other men answer the HIV serostatus question with a non-response, such as Do I look like I have HIV to you? or Why do you even ask me a question like that? with the hope that these responses will cause enough discomfort in the questioner that he will drop the subject and proceed with the sex. Speaking about answer dodging, R800 noted: I don't tell them anything. It's just none of their business, you know? I mean, if they ask me, it's still none of their business, and I don't tell them nothin'. Me having HIV is my business, not theirs.

Convenient omission of information or answer dodging may be considered to be a type of gift giving and a type of stealthing because the HIV-infected man knows that he has HIV, yet actively takes steps to avoid disclosing his
HIV serostatus to his HIV-negative sex partners even when they ask him point-blank about it. As another example of stealthing, an even more passive approach to gift giving entails the adoption of a Don't ask, don't tell policy toward HIV serostatus disclosure. Here, HIV-positive men knowingly have unprotected sex with other men whose HIV serostatus may or may not be known to them; but the HIV-positive men do not disclose their HIV serostatus unless they are asked directly about it. Many of the men participating in the Bareback Project reported that most of their sex partners do not ask them about their HIV serostatus. Thus, they are able to engage in unprotected sex, even with HIV-negative partners, because they are not forced to answer questions about their serostatus. The qualitative notes for R867 illustrate this approach: To date, he has told very few people about his [HIV-positive] serostatus. That includes his sex partners, to whom he only discloses it if they ask him about it. He will admit to being HIV-positive if they ask him about his HIV serostatus; if they do not, he does not disclose it to them. Interestingly, he prefers to have sex with men who are HIV-negative, apparently because he perceives them to be less likely to be capable of transmitting sexually transmitted infections to him. R867 is also unconcerned with his partners' HIV serostatus or their sexual history, and discusses neither with potential sex partners before having sex with them.

Additional insights into the Don't ask, don't tell practice may be found in R877's comments: I live in a don't ask, don't tell world. It's socially unacceptable now to ask [other men about their HIV serostatus]. If I ask [ them whether or not they are HIV-positive], then I don't get laid. ... I'm a world class athlete and a horny guy. I like to have sex, and I want to have sex. If guys won't have sex with me because I want to talk about HIV with them, then I just won't talk about HIV with them. That way, I can still get laid. Otherwise, I'd be 49 years old and frustrated. . . But I make it a point of taking advantage of every opportunity I can afterward, after we're done having sex, to talk with them about it [HIV].

Likewise, R949's comments are illuminating on this subject, as are the interviewer's notes immediately following them: I use a 'Don't ask, don't tell' approach with men and sex. I assume that if they want to know, they'll ask. And then I always tell them the truth. But if they don't ask, I assume that they don't care or don't want to know that I'm positive. [Interviewer notes: All of the sex that $R 949$ reported having during the preceding 30 days was unprotected. It is worth noting that this man answered all but one of the HIV knowledge questions correctly, too; so he is well aware of the risks that he is taking and posing to his partners.] In the most rigid definition of stealthing as a form of gift giving, in which the intentional transmission of HIV to an unaware HIV-negative man is taking place, these Don't ask, don't tell practices may not qualify as gift giving, because the intent to transmit HIV is questionable. But as noted earlier, some scholars label these practices as opportunistic gift giving because they entail the purposeful withholding of HIV-related information that, had it been disclosed to one's sex partner(s) prior to engaging in sex acts, might have led some of them to choose not to engage in risky sex with a particular individual. By knowingly engaging in sexual practices that have a high potential for infecting HIV-negative partners and then withholding one's HIV-positive serostatus information from these partners (as opposed to disclosing it up front), Don't ask, don't tell stealthing may be construed as a type of passive or opportunistic gift giving.

\section{Discussion}

\section{Potential limitations}

As with any research study, the present study has a few potential limitations. First, as with most research data on sexual behaviors, the data in this study are based on uncorroborated self-reports. Therefore, it is unknown whether participants underreported or overreported their involvement in risky behaviors. The study's reliance upon self-reported data is acceptable, however, as other authors of previous studies conducted with similar populations have reported good levels of data quality (e.g., reliability and validity) in their research. 11 This is particularly relevant for self-reported measures that involve relatively small occurrences (e.g., number of times having a particular kind of sex during the previous 30 days), which characterize the substantial majority of the data collected in this study. ${ }^{12}$ Other researchers have also commented favorably on the reliability and/or the validity of selfreported information in their studies regarding topics such as condom use and substance use/abuse. ${ }^{13-16}$

Second, this paper was based on analysis of a relatively small sample size, particularly with regard to the behaviors pertaining to gift giving. Moreover, some of the concepts introduced in this research (e.g., generationing and stealthing) are either new to the scientific literature or among the first to be reported in the literature, leaving unknown the extent to which these behaviors occur. It would, of course, have been preferable to have access to a more robust sample size, so that greater confidence could be placed upon the findings. The present study's findings should, therefore, be construed as preliminary until such time that further research can be undertaken. 


\section{Conclusions}

Despite these limitations, a number of interesting and important findings come from this study. First, as other researchers have documented with regard to bug chasing - which is the true counterpart to the gift giving phenomenon that is the focus of the present study gift giving appears to be an infrequent practice among MSM who use the Internet. In the present study of men using the Internet specifically to find other men with whom they could engage in unprotected sex, approximately 1 HIV-positive, unprotected-sex-seeking man in 22 was an active/committed gift giver - that is, someone who intentionally was trying to infect other men with HIV. This figure is comparable to the estimates provided by other researchers, ${ }^{2-4}$ which is noteworthy in light of the different manner in which the present study's prevalence estimate was derived when compared to those provided by these other researchers. When a more-relaxed definition of gift giving is employed, such that men who are indifferent to the transmission of HIV to their sex partners are included in the definition of gift givers (what might be termed passive or opportunistic gift givers), the prevalence of this phenomenon rises greatly, to more than $40 \%$ of the population of HIV-positive, unprotected-sex-seeking men.

Regardless of which definition of gift giving one uses, the prevalence figures are sufficiently high as to raise concerns about the transmission of HIV to currently-uninfected MSM. One of the main implications of this finding is that interventionists need to work with HIVpositive men to bolster their rates of HIV serostatus disclosure, particularly to new sex partners who are unaware that they are about to have sex with someone who is HIV-positive. Published studies have shown that greater partner communication regarding HIV serostatus is associated with reduced involvement in risky sexual practices. ${ }^{17,18}$ Role playing exercises, in which HIV-positive men can rehearse specific strategies for informing potential sex partners about their HIV serostatus and simultaneously receive feedback and constructive suggestions about better ways to discuss this topic with potential sex partners, might prove to be a helpful way of accomplishing this. Another implication of the present study's prevalence-related findings for gift giving is that interventionists need to work with HIVnegative men to improve their partner communication skills as well. These men need to take personal responsibility for maintaining their sexual safety, and they must do this on a consistent basis. Many HIV-negative MSM do not engage in this practice at all, or do so inconsistently, leaving themselves vulnerable to contracting HIV. Once again, role playing exercis- es might be an effective way of teaching HIVnegative, unprotected-sex-seeking MSM specific strategies they can use to broach the subject of HIV serostatus, so that they can feel more comfortable discussing this with potential sex partners.

Another contribution that the present study makes to the scientific literature is its introduction of the concept of generationing as a type of gift giving behavior. In preparing this article, the present author was unable to locate any information in the scientific literature about this practice. Consequently, much remains to be learned and documented regarding the behavior. Future studies, especially those undertaken with a qualitative methodology (or a mixed-methods approach), are needed. In all likelihood, generationing is a lowprevalence practice, even among barebacking MSM; but among persons engaging in this behavior, it is one that carries with it an extremely high risk of transmitting HIV. For that reason alone, researchers and HIV prevention/intervention practitioners must be made aware of generationing. Bareback sex parties, which are popular among many Internet-using barebacking MSM, ${ }^{19}$ may be especially popular among men wishing to engage in generationing, because these parties make it possible for several men to come together to have sex with multiple persons in one session. Those who are interested in participating in generationing may find bareback sex parties to be a particularly convenient way to bring their generations together in a setting in which currently-uninfected but willing sex partners may be found and infected successfully. Again, future studies need to learn much more about generationing: How prevalent is this behavior? What factors are associated with involvement in this practice? How do men who are interested in engaging in generationing find one another? How often do men participating in one person's generationing chain become sufficiently enthralled with the practice that they decide to initiate a generationing chain of their own? At present, the answers to these fundamental questions are unknown.

Another contribution made by the present study is its findings regarding yet another type of gift giving, namely stealthing. Once again, very little is known about this practice, particularly in terms of how prevalent it is, who engages in it (demographically speaking), what factors are associated with involvement in the practice, the circumstances that lead some men to engage in stealthing, or the specific motivations for wanting to infect an unaware partner with HIV. Although it is probable that, like generationing, stealthing is a low-prevalence activity among barebacking MSM, it is a practice that has major implications for men's health whenever it is undertaken. Once again, the key to combating the dan- gers inherent in stealthing lies in enhancing partner communication and HIV serostatus discussion/disclosure skills, especially among HIV-negative men. Another possible way to combat the practice of stealthing - one that is likely to be effective with only a portion of the men who engage in the practice - would be to alert these men to the legal ramifications of their actions. Many states now treat the intentional transmission of HIV as a crime, invoking existing laws governing assault as the basis for such criminality;20 and some men who knowingly infect HIV-negative men with HIV may be unaware of the legal statutes where they live. Making them aware of the illegality of their actions may lead some of them to reconsider their involvement in stealthing. To the extent that these men find stealthing to be a highly erotic sexual practice, though, heightening awareness of potential legal consequences probably will not be sufficient to eradicate the behavior.

Gift giving, in whatever form it happens to take in a particular situation, is an HIV transmission practice that is not well-understood at this time. Much more research is needed on this subject, particularly in light of recent evidence suggesting that the practice may be increasing in prevalence. ${ }^{3,4}$ Reliable data are needed to pinpoint more accurately the prevalence of the behavior because currently we simply do not know how (un)common gift giving is among HIV-positive MSM. Additionally, studies are needed to identify what characteristics differentiate active or committed gift givers from those who might be described as passive or opportunistic gift givers, as well as what characteristics differentiate gift givers from their barebacking HIV-positive MSM counterparts who do not wish to transmit HIV to their sex partners. Identifying such characteristics can help future intervention programs to offer targeted efforts to prevent the spread of HIV among MSM. Also needed are studies that can illuminate the reasons why men engage in gift giving behaviors. Understanding why these persons want and try to infect their sex partners with HIV may help interventionists and HIV prevention workers to develop strategies to counteract these persons' actions. Finally, additional research is needed to learn more about the gift giving-related phenomena of generationing and stealthing as well as any other currently-unknown ways in which gift givers endeavor to infect their sex partners with HIV.

\section{References}

1. Moskowitz DA, Roloff ME. The existence of a bug chasing subculture. Cult Health Sex 2007;9:347-57. 
2. Dawson AG Jr., Ross MW, Henry D, Freeman A. Evidence of HIV transmission risk in barebacking men-who-have-sexwith-men: cases from the Internet. J Gay Lesbian Psychother 2005;9:73-83.

3. Grov C, Parsons JT. Bug chasing and gift giving: the potential for HIV transmission among barebackers on the Internet. AIDS Educ Prev 2006;18:490-503.

4. Tewksbury R. Click here for HIV: an analysis of Internet-based bug chasers and bug givers. Deviant Behav 2006;27:379-95.

5. Gauthier DK, Forsyth CJ. Bareback sex, bug chasers, and the gift of death. Deviant Behav 1999;20:85-100.

6. Moskowitz DA, Roloff ME. The ultimate high: sexual addiction and the bug chasing phenomenon. Sex Addict Compuls 2007;14:21-40.

7. Glaser BG. Doing grounded theory: issues and discussions. Mill Valley: Sociology Press; 1998.

8. Strauss AL, Corbin J. Basics of qualitative research: techniques and procedures for developing grounded theory. 2nd ed. Newbury Park: Sage Publications; 1998.

9. US Census Bureau. Profiles of general demographic characteristics 2000. Washington, DC: U.S. Government Printing Office; 2001.

10. U.S. Census Bureau. GCT-PH1. Population, housing units, area, and density: 2000. Washington, DC: U.S. Government Printing Office; 2000.

11. Schrimshaw EW, Rosario M, MeyerBahlburg HFL, Scharf-Matlick AA. Testretest reliability of self-reported sexual behavior, sexual orientation, and psychosexual milestones among gay, lesbian, and bisexual youths. Arch Sex Behav 2006;35:225-34.

12. Bogart LM, Walt LC, Pavlovic JD, et al. Cognitive strategies affecting recall of sexual behavior among high-risk men and women. Health Psychol 2007;26:787-93.

13. Morisky DE, Ang A, Sneed CD. Validating the effects of social desirability on selfreported condom use behavior among commercial sex workers. AIDS Educ Prev 2002;14: 351-60.

14. Anglin MD, Hser Y, Chou C. Reliability and validity of retrospective behavioral selfreport by narcotics addicts. Eval Rev 1993;17:91-103.
15. Jackson CT, Covell NH, Frisman LK, Essock SM. Validity of self-reported drug use among people with co-occurring mental health and substance use disorders. J Dual Diagn 2004;1:49-63.

16. Yacoubian GS Jr., Wish ED. Exploring the validity of self-reported ecstasy use among club rave attendees. J Psychoactive Drugs 2006;38:31-4.

17. McCready KC, Halkitis PN. HIV serostatus disclosure to sexual partners among HIVpositive methamphetamine-using gay, bisexual, and other men who have sex with men. AIDS Educ Prev 2008;20:15-29.

18. Rosser BRS, Horvath KJ, Hatfield LA, et al. Predictors of HIV disclosure to secondary partners and sexual risk behavior among a high-risk sample of HIV-positive MSM: results from six epicenters in the U.S. AIDS Care 2008;20:925-30.

19. Pollock JA, Halkitis PN. Environmental factors in relation to unprotected sexual behaviour among gay, bisexual, and other MSM. AIDS Educ Prev 2009;21:340-55.

20. Wolf LE, Vezina R. Is there a role for criminal law in HIV prevention? San Francisco: Center for AIDS Prevention Studies; 2005. 